\title{
Opinion
}

\section{Mindfulness: An Approach to Avoiding Regret}

\author{
Melissa Madeson* \\ Department of Fitness \& Sport Science, USA
}

*Corresponding author: Melissa Madeson, Department of Fitness \& Sport Science, USA.

Received Date: September 30, 2019

Published Date: October 16, 2019

\section{Introduction}

Do you have any regrets in life? Missed opportunities, impulsive decisions, time lost, wasted or filled with fear, anger and bitterness? It's been said that no one gets to the end of life and wishes they had worked more hours or made more money. At the end of life, most people wish they had spent more time with loved ones, experienced more moments of awe and inspiration, laughed, cried, traveled, seen the sun rise, the sun set, completed a bucket list...

I would make the argument that mindfulness is the preventative medicine for these regrets. According to John Kabat-Zinn, a leading researcher and expert in the field, mindfulness is the "awareness that arises through paying attention, on purpose, to the present moment, without judgement" [1]. Nilsson H [2] conceptualized a four-dimensional model of mindfulness which includes physical (body), mental (mind), social (group) and existential (spiritual). This model engages the participant to develop awareness and appreciation of the self, others and the deeper meaning and purpose in life.

We can further categorize the concept of mindfulness in two main areas. First is the specific practice of mindfulness. This is the sitting meditation, a body scan and/or an intentional and mindful yoga practice. Time is set aside to practice the skill of mindfulness or what some might call time to "meditate". The second type of mindfulness practice is the act of taking the skill or concept into daily life and activities. It is this type of mindfulness that prevents the sting of regret and heals the heart of loss.

As a yoga teacher, practitioner, university professor and therapist, teaching mindfulness can be as simple as having clients focus solely on the breath for five minutes. In this practice the client will focus all their attention on the breath. The focus is on all sensations associated with the breath...the sound, the length, if the breath is coming out of the nose or the mouth. Is the breath deep or shallow? This purposeful attention is without judgement and without trying to alter what is happening. It is about being curious and fully present. As the mind wanders, it is about noticing what the mind goes to and gently encouraging it to turn back to the breath.

As a University professor I take this practice into the classroom full of college students in my Wellness for Life course as we learn about stress. Systematically and predictably students initially roll their eyes. They hate it. Their feet are tapping, hands are twitching and sighs of annoyance abound. But after several attempts, students are amazed at how quickly and often the mind goes to various places. With practice, even highly anxious 20 year-olds with ADHD can learn the benefits of quieting, slowing and calming the mind and body.

There are benefits to doing a mindful breathing exercise all alone but the true benefits come when the practice is applied to daily life. When you can move through your day truly experiencing each moment as it comes. Greeting each moment with awareness, on purpose, without judgement.

When was the last time you did this? When have you had an interaction with another human...mindfully? What would it look like to be fully present with them? To engage in listening, bringing awareness to their gestures and facial expressions, to share their thoughts and emotions?

What would it be like to eat a meal, mindfully. To smell the fresh bread, notice the texture and color of the apple, feel the soft fuzz of a peach and taste the juiciness of a ripe strawberry. To feel the texture and taste change in your mouth as you chew and enjoy the residue of that taste as you swallow it, imagining how it will nourish the cells of your body.

Take your mundane, daily tasks...taking a shower, driving to work, cleaning a dish left in the sink.... try to do some of these mindfully. Slow down, notice the smells, textures, sensations, every aspect of the experience and fully soak it in. 
In our busy lives we rarely do this. We miss so much. We take for granted. We lose sight of the little things and in turn, miss the ability to see the beautiful tapestry of life unfolding. And we look back and have regrets. If we could learn to practice mindfulness, to slow down and experience the moments in life we might find a deep satisfaction, fullness and an appreciation for the high points, the low points, the grand experiences and the minute daily tasks knowing that we are truly alive.

\section{Conflict of interest}

No conflict of interest.

\section{References}

1. Kabat Zinn J (1990) Full catastrophe living. Delacorte Press, USA.

2. Nilsson H (2014) A four-dimensional model of mindfulness and it's implications for health. Psychology of Religion and Spirituality 6(2): 162-174.

\section{Acknowledgment}

None. 